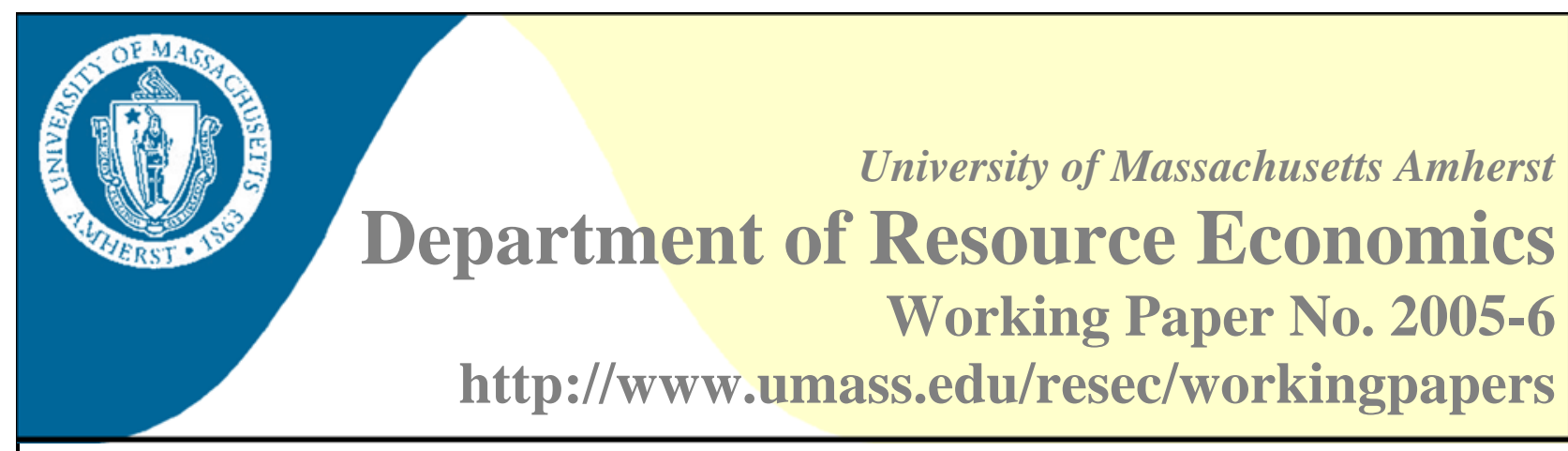

\title{
Landowner Driven Sustainable Forest Management and Value-Added Processing
}

\author{
David T. Damery ${ }^{1}$
}

Abstract:

The Massachusetts Woodlands Cooperative, LLC (MWC) is working to help members conduct sustainable forestry of the highest standards while increasing financial returns from harvest activities. The forests of Massachusetts, the 3rd most densely populated of the United States, are threatened. Decades of high grading and the threat of conversion to alternative use present challenges for maintaining a forested landscape. Despite being 60\% forested Massachusetts imports approximately $98 \%$ of the wood fiber that its citizens consume.

MWC is a forest management, processing and marketing cooperative organized by and on behalf of forest landowners in western Massachusetts. The cooperative was envisioned in 1999, incorporated in 2001, gained Forest Stewardship Council (FSC) land management certification in 2003 and is currently in the business-start-up and early growth stage. An umbrella group certification protocol was developed to provide cost-effective forestland management certification. Members benefit from cooperative management of harvest operations, above market stumpage payments, and value-added processing and production including marketing traditionally low value and small diameter material. The added revenue from developing these new markets is used to fund both timber and non-timber related management activities that landowners value. The cooperative partners with local wood processing businesses to spur community economic development.

Keywords: Forest certification, value-added processing, cooperative, landowner, marketing

JEL Classification: O13, Q01, Q13, Q23, Q56

\footnotetext{
${ }^{1}$ David T. Damery, Department of Natural Resources Conservation University of Massachusetts, Holdsworth Hall

Amherst, MA 01003

E: ddamery@forwild.umass.edu P: 413-545-1770 F: 413-545-4358
} 


\title{
Landowner Driven Sustainable Forest Management and Value-Added Processing
}

\author{
David T. Damery ${ }^{1}$
}

\begin{abstract}
The Massachusetts Woodlands Cooperative, LLC (MWC) is working to help members conduct sustainable forestry of the highest standards while increasing financial returns from harvest activities. The forests of Massachusetts, the $3^{\text {rd }}$ most densely populated of the United States, are threatened. Decades of high grading and the threat of conversion to alternative use present challenges for maintaining a forested landscape. Despite being $60 \%$ forested Massachusetts imports approximately $98 \%$ of the wood fiber that its citizens consume.

MWC is a forest management, processing and marketing cooperative organized by and on behalf of forest landowners in western Massachusetts. The cooperative was envisioned in 1999, incorporated in 2001, gained Forest Stewardship Council (FSC) land management certification in 2003 and is currently in the business-start-up and early growth stage. An umbrella group certification protocol was developed to provide cost-effective forestland management certification. Members benefit from cooperative management of harvest operations, above market stumpage payments, and value-added processing and production including marketing traditionally low value and small diameter material. The added revenue from developing these new markets is used to fund both timber and non-timber related management activities that landowners value. The cooperative partners with local wood processing businesses to spur community economic development.
\end{abstract}

KEYWORDS. Forest certification, value-added processing, cooperative, landowner, forest management, Massachusetts, marketing

The forests of Massachusetts, the $3^{\text {rd }}$ most densely populated of the United States, are threatened. Decades of high grading and the threat of conversion to alternative use present challenges for maintaining a forested landscape. Despite being 60\% forested Massachusetts imports approximately $98 \%$ of the wood fiber that its citizens consume. The combined challenges of promoting sustainable forest management and achieving business success while helping Massachusetts become more self-sufficient in its consumption of forest products are discussed.

The Massachusetts Woodlands Cooperative (MWC) was formed to help private forest landowners manage their land both sustainably and profitably. MWC relies on the FSC Certification process to guide member's stewardship of their forestlands. In order to fund both timber and non-timber management activities members are coordinating value-added processing activities for their timber harvests. They are developing markets for traditionally low value and small diameter material. The business model they have developed is described in the hope that useful and relevant elements can be replicated elsewhere. The history of cooperative formation is summarized. Management, membership recruitment, financing, and operations are also discussed. Case studies of marketing efforts are presented.

\footnotetext{
${ }^{1}$ David T. Damery, is Lecturer, Dept. of Natural Resources Conservation, Univ. of Massachusetts-Amherst, Amherst, MA, 01003, USA (ddamery@forwild.umass.edu)
} 


\section{SETTING, SUSTAINABILITY AND SELF-SUFFICIENCY}

Massachusetts is home to 6.2 million residents, most of whom live in the eastern half of the State. Though most of the state is forested, the western half hosts the most densely wooded stands of temperate hardwoods and softwoods. The forest has been altered dramatically in concert with changes in land-use over the past 300 years. With the arrival of European colonists and the expansion of an agrarian society, land was cleared for farming over the $18^{\text {th }}$ and much of the $19^{\text {th }}$ centuries. Beginning about 1870, however, the decline in forest was reversed as the center for agriculture progressed westward across the United States (US). Breunig (2003) reports that agricultural land covered $50 \%$ of Massachusetts land area in the late $19^{\text {th }}$ century and has declined to $7 \%$ in 2003.

A significant portion of the formerly agricultural land has re-generated into forest. Forest area increased steadily from a low of about 30\% of land area in 1870 to a high of nearly $75 \%$ in 1960 . The most recent, 1998, forest inventory analysis estimates that $62 \%$ of the land area is forested (Alerich, 2000). Since 1960, development pressures including sub-division for homebuilding have led to this renewed erosion of the forest base.

Even though forest area is losing ground, the growing volume of trees continues upward. Net growth of trees in the western half of the state exceeds the rate of net removals in the east. Single family housing starts, and their construction on large suburban lots has been the primary cause of a loss of forest habitat recently averaging 16 hectares (40 acres) per day (Breunig, 2003). On one hand the growing forest in western Massachusetts represents an opportunity, but on the other, the spread of suburbanization and conversion of forestland poses a growing concern for the forest landowners of Massachusetts.

Much of the re-generated forests of Massachusetts has grown up un-managed. Forest stands are often too densely stocked and contain a high portion of low-grade trees. Land ownership patterns have decreased the average tenure of forest properties. In our increasingly mobile society, property changes ownership more frequently. New landowners may not have had a close relationship to the land prior to their forestland acquisition. They often lack knowledge of forest management principles and practices. Many forest landowners are just now awakening to the fact that actively managing the forest might significantly increase the provision of both timber and non-timber values.

The forests of the region are in a transitional area comprised of both central and northern hardwood and softwood types (Barten, 2001). Though the tree volume continues to increase overall, it is not uniform across species. The rate of growth in volume across species reflects, in part, the relative market values and merchantability of the predominant species. In recent decades northern red oak and eastern white pine have commanded the highest stumpage prices. Their market appeal is reflected in the rate of growth of the sawtimber resource as measured by the ratio of growth to removals. Alerich (2000) reports that the higher valued species had the smallest growth/removal ratios. Northern red oak sawtimber had a ratio of 1.7 and eastern white pine, 2.6. The lesser valued species of eastern hemlock and red maple had ratios of 14.9 and 6.5 
respectively. This represents a second area of concern for forest landowners. If their long term objective includes improving timber values, they may have a desire to shift the species mix on their properties. This brings up the problem of finding markets for the traditionally less valued species of red maple and hemlock which are the $2^{\text {nd }}$ and $4^{\text {th }}$ most abundant species by growing stock volume. Traditionally, thinning cuts for stand improvement have been difficult to cost justify. If the species targeted for thinning cuts are of low value in the marketplace, the problem of funding these intermediate harvests is exacerbated. Figure 1 shows the percentage of growing stock volume for all species in Massachusetts from the most recent, 1998, forest inventory analysis (Alerich, 2000).

Wood is a preferred material for many of the items we consume in our daily lives. Its many uses include; the daily newspaper, mail-order catalogs, lumber and building materials, furniture, cardboard packaging of consumer products, and in the shipping pallets that almost all of our goods are transported on. Wood consumption in Massachusetts is estimated at over 13 million cubic meters annually but harvests from state timberland amounts to only 300,000 cubic meters. One goal of the MWC is to help Massachusetts become more self-sufficient in it's consumption of wood products.

Berlik, Kittredge and Foster (2002) highlight the inconsistency of US consumers desire for global environmental protection and the reality of their current level of forest products consumption. In addition to reducing consumption they recommend an increased level sustainable production of locally produced wood products. With almost $80 \%$ of the forestland owned by private forest landowners a challenge to this objective is landowner education.

\section{LANDOWNER PROBLEMS AND ISSUES}

Though we may recognize, from a policy perspective, a need for higher levels of local production, and that the forest continues to grow in volume despite habitat loss, the decision to actively manage Massachusetts' forests still lies with individual landowners. Apart from the "macro" perspective on demand and supply, these individual landowners have their own set of problems and goals. Private forest landowners have many values and ownership objectives beyond revenue from timber harvesting.

To gain insight into the values of private forest landowners Damery (2001) surveyed 232 western Massachusetts forest landowners who had active forest management plans. When asked to rate their level of interest in 8 different forest issues, landowner income came in $5^{\text {th }}$. Wildlife habitat, tree and plant quality, ecosystem health and water quality all ranked higher. Rankings for all options are shown in Table 1.

\section{Table 1 HERE}

Clearly, these landowners desire to maintain and improve their forestlands. More importantly, timber management is only one objective among many. Achieving the various landowner objectives is costly. Timber harvesting is often looked on as the means to finance other activities. A confounding factor is the need to improve the overall stand quality for long-term management. This requires thinning or selective harvests. As noted earlier a significant portion 
of the regenerated forest has come back in an un-managed state. Small diameter, crooked stem, or low value species that might be targeted for removal, often bring little or no value in the market place. This problem of finding markets for this material has been identified as a key goal by the landowners of the MWC.

Traditional market factors also stand in the way of a solution regarding the financing of thinning cuts. Local markets for small diameter wood are thin. An example is the market for firewood. In the more urban, eastern, part of the state firewood delivered to the household might command as much as \$300 USD per cord (2.3 cubic meters). Local markets in western Massachusetts, closer to the forest resource, may only command $1 / 2$ this price. A second potential disincentive to executing thinning cuts is the traditional compensation mechanism for consulting foresters in the region. Many forest landowners contract with consulting foresters to develop management plans, and to organize and supervise harvest activities. When managing a harvest activity the consulting forester is typically paid as a percentage of the stumpage fee that is achieved in the harvest. A thinning harvest has much lower potential to generate stumpage fees than does a mature harvest. This has sometimes led to the practice of high grading, referred to as "cut the best and leave the rest”. Recent outreach and forestry education activities are raising the consciousness of both foresters and landowners and this is serving to lower the level of high grading activity.

Even among landowners who have become aware of the need for active forest management there are reasons for seeking an alternative to the current market mechanisms for selling stumpage. An example is prior bad experience in either a consulting forester relationship, or with a harvest experience. In any commercial experience, whether it is an evening out dining, shopping, or harvesting a woodlot there is a risk of having a poor customer service experience. Landowners may not have gotten along in a consulting forester relationship. Similarly, landowners may have been disappointed with the result of a past logging job. The post-harvest condition of the woodlot is often the cause. How slash was handled or excessive residual stand damage are often cited as reasons for the dissatisfaction.

\section{COOPERATION AS A SOLUTION}

A small group of landowners saw a potential solution to many of these issues. They believed that by banding together they would be better able to improve their knowledge of good forestry and address market and customer service quality issues. Through peer-to-peer knowledge sharing and by developing contacts with resource providers in the forestry area they felt they would be able to expand their knowledge of best forest management practices.

Economies of scale provide the potential to develop better markets for the small diameter and lesser-valued materials. Coordinated harvest activities can lower the unit costs of harvest. Costs are lowered through more efficient use of foresters and harvesters. By combining their management efforts a group of landowners are able to offer a steady stream of forest products, over time, from a much larger combined forest area. Larger harvest volumes, and more reliable supply can generate higher timber sales revenues. Similar arguments apply to the potential for developing markets for the low-grade material. 
Economies of scope are achieved through coordination include performing additional non-timber management activities such as those identified in the landowner survey (Damery, 2001). Looking beyond individual landowner objectives, a cooperative of landowners is positioned to achieve broader "landscape" level objectives. This has potential to improve wildlife habitat, and recreational activities for example.

Through sharing their past experiences with foresters and harvesters, cooperative members are able to identify the quality of service expected from service providers. This knowledge is used to identify professionals with expertise in particular kinds of harvest operations. For example, when forest conditions require very low impact harvest operations, loggers with the necessary equipment can be identified.

\section{THE COOPERATIVE FORMATION PROCESS}

Formed from a core of interested, like minded, forest landowners in the hill-towns of western Massachusetts, the organizing process spanned a period of two years. The Limited Liability Corporation (LLC) form of organization was selected based on ease of formation and operating flexibility. Though formed as an LLC the MWC operates as a cooperative where each member has one vote, and profits are returned to the members based on patronage. In the case where profits are available to distribute back to members, they are apportioned on the basis of the stumpage value that each member contributed to the cooperatives value-added operations that year. The MWC is a for-profit organization and membership is by invitation. An open form of communication, and consensus decision-making form the heart of the organizational culture. In addition to the landowner founders, a group of resource professionals was assembled to advise and inform the membership regarding forestry and business operations. These included individuals with relevant expertise from the forest products industry, legal, accounting, university, state forestry agency, consulting forestry, and non-profit groups interested in cooperative formation and economic development.

The mission statement for the cooperative reads

"The Massachusetts Woodlands Cooperative (MWC) is a forest landowner management, processing and marketing cooperative organized by and on behalf of forest landowners in western Massachusetts. The mission of MWC is to maintain the environment and character of western Massachusetts through the protection, enhancement and careful economic development of one of the region's most plentiful resources, the forest.”

Three primary objectives appear in this statement. The first is a desire to perform forest management in an environmentally responsible fashion. The second is to coordinate value-added operations in order to improve the financial returns to the landowner. The third is the desire to conduct business operations with local partners in order to foster local community economic development. The process of green certification and pilot projects leading up to commercial operations are described next.

\section{COST EFFECTIVE FOREST CERTIFICATION}

MWC members have a strong desire to conduct forestry activities consistent with the world's highest standards. The FSC green certification standard was chosen at the outset as a recognized measure for achieving this goal. With the help of grant funding from the US Department of Agriculture, Forest Service, the MWC developed a protocol for certifying members forestlands. 
Working with Univ. of Massachusetts-Amherst faculty and students, and state forestry personnel an "umbrella” protocol for group certification was developed. This was designed to provide a cost-effective way for small landowners to have their forests certified as being sustainably managed. MWC’s application for FSC group certification was approved in 2003.

One requirement for MWC's group certification is that each member have an approved forest management plan that addresses the 9 guiding principles of FSC. The majority of landowners joining MWC are already covered under a forest management plan. Typically these plans are part of a Massachusetts forest property tax reduction program known as Chapter 61. This program requires a 10 year commitment to keep the land in it's forested state and to follow the management activities that are described in the plan. Chapter 61 participants are eligible for a property tax reduction of up to $95 \%$ of the assessed value of the forestland. Penalties are applied for any early withdrawal from the plan. The required forest management plan is quite comprehensive. Landowners typically contract with a consulting forester to survey their property and work with them to identify specific landowner goals that are written into the plan. Members with these types of plans need only slight modifications, at a modest cost, in order to upgrade their "Chapter 61" plans so that they meet the broader FSC guidelines.

The annual audit fee is approximately $\$ 1,500$ USD, which is covered by the cooperatives general operating expenses. Apportioned across more than 40 members this represents roughly \$40 USD per member annually.

In order to keep audit costs to a minimum MWC acts as an internal auditor to ensure compliance with FSC guidelines. Staff, members and volunteers including forestry faculty from the University survey each member's property annually. Harvest activities performed on member properties are reviewed by MWC staff. Smartwood, part of the Rainforest Alliance, has been the FSC auditor. Having the internal review team allows Smartwood to select a random sample of all member properties to review during their annual audit. By selecting a sub-set of all member properties, the time and expense of the outside auditor can be kept to a reasonable minimum. Documentation of MWC's internal audit team are also reviewed as part of the annual outside audit. This process provides a low-cost method for achieving the first of MWC's core mission objectives, sustainable forest management.

\section{OPERATIONS AND MARKETING}

Three part-time staff, currently manage MWC operations. Two co-executive directors manage; membership, harvest activities, value-added production, and sales and marketing. An office manager handles day-to-day clerical operations for the cooperative. The cooperative contracts a part-time bookkeeper and retains accounting and legal help as needed.

Staff report to a board of directors and the general membership. Staff are presently funded through a major US Dept. of Agriculture, Rural Business-Cooperative Services Grant. These funds, awarded in 2004, are designed to provide start-up working capital that will enable the MWC to be financially self-sustaining by 2007. Other income is generated by membership fees, and product sales. An annual membership fee of \$85 USD has been assessed each member for the years 2004 and 2005. The MWC business plan was developed using data from pilot projects 
where trees were harvested from member properties and then managed through a variety of value-added processing steps. The break-even production rate is projected to be 1,200 cubic meters (350 MBF) of processed timber annually. Steps in the value-added process are coordinated by MWC staff. Staff consult with landowner members and their consulting foresters to purchase stumpage at above market rates. In addition, staff contract with independent loggers for harvesting, sawmills for primary processing, dry kilns, and molders for secondary processing into flooring and other products.

Manufactured products include: rough sawn lumber, finished tongue-and-groove hardwood flooring, timbers and logs. These products are marketed to local homeowners, building contractors, and architects for inclusion in residential and commercial construction. Several pilot-project case studies were conducted to produce hardwood flooring, timbers, poles and lumber. Data was gathered from each of these projects including; yields, costs, prices, and time involved. The current business plan relies heavily on the field experience gained during the pilot project stage.

Pilot projects included production of hardwood flooring, and the harvest and production of black locust for lumber, posts, railings, and firewood. These projects required coordination of: landowners, consulting foresters, loggers, trucking, sawmilling, drying, and value-added processing (molder). Higher than expected yields were achieved, but at the added cost of additional labor time and management expense (Campbell, 2004).

The flooring project began when a cooperative member offered 30 logs, mostly of black cherry, that were left over from a harvest and lumber milling project. This material was of relatively small diameter and low to medium low in quality. This provided an opportunity to experiment with the production of strip hardwood flooring. Strip flooring can be sold in relatively narrow widths and short lengths. The material was trucked to a local circular saw mill, owned by another cooperative landowner member where it was milled and dried. The dried material was trucked to custom moulder for production of tongue and groove flooring in a variety of widths. Costs were tracked throughout the process and the material was marketed at a competitive price. Two factors should be noted in this project. The first is that the species, black cherry, currently commands a premium price in the marketplace. Marketing a less popular species, such as red maple, will present much lower margins. Secondly, the flooring material was marketed locally as a "natural" or "character grade" flooring, and was not separated into traditional grades of flooring. This "run of the log" grading process requires education of the consumer in the market place.

A second pilot project involved the harvest of a small stand 0.4 hectare ( 1 acre) of black locust located in close proximity to a cooperative members home. As black locust is not a common species in the region, this project involved finding a potential buyer for the harvest and processed material prior to project start. One of the highest and best uses of black locust is in exterior applications. Black locust features natural disease and rot resistance. A buyer was identified who specializes in the production of outdoor walkways. MWC co-director Susan Campbell acted as project coordinator, working with the landowner, forester, logger (who also purchased the end material), and sawmiller. By carefully considering the particular end-uses that the buyer was interested in, a much greater volume of material was yielded than either the initial forester 
inventory, or subsequent log-tally would indicate. Campbell(2004) estimated that overall sawlog volume recovery was 2.2 times what might be expected in a conventional harvest. The estimated value of products recovered was even greater. Value at the log landing was estimated at \$3,547 USD under the cooperative managed scenario vs. an estimated \$1,158 USD that might have been received in a conventional stumpage sale.

The pilot projects illustrated the potential to return higher revenues to member landowners through value added processing. If the cooperative is to succeed on an expanded level, markets must be found to absorb a much higher level of production. Two primary markets have been identified as holding the best potential. The western Massachusetts region has a reputation for cultivating "buy-local" markets. There is a minority, but significant, portion of the consuming public that prefer to buy local material over, possibly less expensive, products imported from outside of the state. On a more global scale, mechanisms such as the Low-Energy and Environmental Design (LEED) architectural standards promote the purchase of locally produced materials. Marketing materials and promotion campaigns for MWC produced products will promote this buy-local message.

The second major market opportunity is associated with sustainable management and green certification. A different, but perhaps overlapping, consuming public appreciates the notion of sustainable forest management. To support the expansion of green certified forest products, the MWC has embarked on a project to certify local forest products businesses. A group "chain-ofcustody" umbrella protocol has been developed and several local businesses are in the process of applying for certification. The "chain-of-custody" process ensures that businesses can document their material purchases and manufacture of products that utilize "green certified" wood. This provides the end-consumer with an audited level of assurance that the product they are purchasing can indeed be traced back to material that came from a sustainably managed forest.

\section{MEMBERSHIP GROWTH AND THE FUTURE}

Growth of the MWC has been incremental. Conservative governance has avoided large-scale capitalization and preference is given to working with existing businesses in the region's forest products industry. Challenges remain in expanding the membership to enable balancing the harvest activities of the membership with the market demand for MWC value-added products. Current members of MWC include 42 individuals, families and organizations with 1,900 hectares (4,600 acres) of forestland. The average property size is approximately 45 hectares (110 acres).

One key goal for the MWC is to develop value-added markets for traditionally under-valued and smaller diameter wood. The economies of scale and scope provided by the Coop are focused on the identification of higher value markets for these less-valued materials. If successful, more timber stand improvement work can be conducted on member properties that will increase timber growth rates, stumpage values and the provision of non-timber benefits in the long-term.

If MWC can achieve its management and marketing goals, additional revenues will be generated for the member landowners that should provide an incentive to keep their property in forestry. Improved forestry returns combined with practicing the highest recognized standards of 
sustainable forestry will enable members to preserve the forested landscape of western Massachusetts for future generations. 


\section{REFERENCES}

Alerich, C. L. 2000. Forest statistics for Massachusetts: 1985 and 1998. Resour. Bull. NE-148, U.S. Dept. of Agriculture, Forest Service, Northeastern Research Station, Newtown Square, PA, USA

Barten, P. K., D. Damery, P. Catanzaro, J. Fish, S. Campbell, A. Fabos and L. Fish. 2001. Massachusetts Family Forests: Birth of a Landowner Cooperative, Journal of Forestry 99 (3): 23-30

Berlik, M. M., D. B.Kittredge, and D, R. Foster. 2002. The Illusion of Preservation: A Global Environmental Argument for the Local Production of Natural Resources. Harvard Forest, Harvard University, Petersham, Massachusetts, USA, Harvard Forest Paper No. 26.

Breunig, K. 2003. Losing Ground: At What Cost? Summary Report, Mass Audubon, Lincoln, Massachusetts, USA, November, 2003

Campbell, S. M. 2004. Profiles from Working Woodlands. Massachusetts Woodlands Institute, Montague, Massachusetts, USA, June, 2004

Damery, D. T. 2001. Report on the Western Massachusetts Forest Landowner Interest Survey. White Paper, University of Massachusetts-Amherst, Dept. of Natural Resources Conservation, Amherst, MA, USA 
Table 1 - Landowner Rankings of Interest in Forest Issues

$$
(n=232)
$$

\begin{tabular}{|l|l|}
\hline Issue & $\begin{array}{l}\text { Percentage of Respondents who ranked } \\
\text { issue as “Strong” or “Moderate” Interest }\end{array}$ \\
\hline Wildlife Habitat & $58 \%$ \\
\hline Tree and Plant Quality & $56 \%$ \\
\hline Ecosystem Health & $52 \%$ \\
\hline Water Quality & $38 \%$ \\
\hline Landowner Income & $36 \%$ \\
\hline Aesthetics & $16 \%$ \\
\hline Recreational Opportunity & $14 \%$ \\
\hline Local Economy & $10 \%$ \\
\hline
\end{tabular}


Figure 1

Volume of Growing Stock by Species, 1998

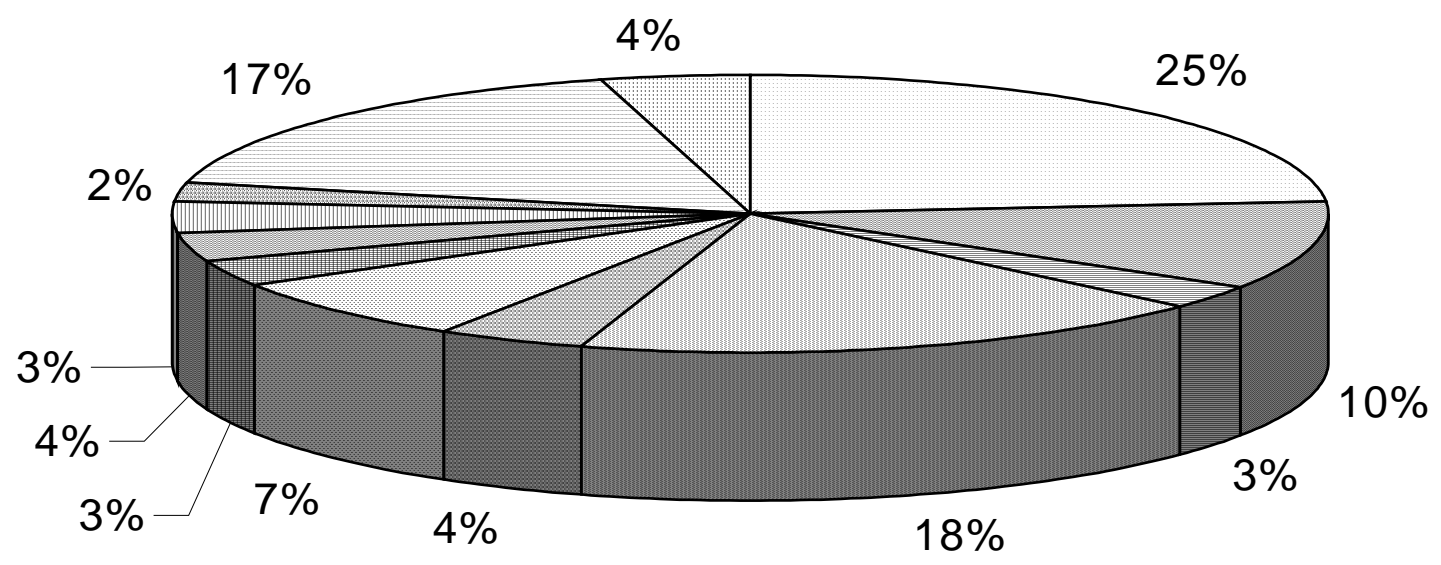

$\square$ White Pine

$\square$ E. Hemlock

Other Softwoods

$\square$ Red Maple

$\square$ Sugar Maple

$\square$ Birches

$\square$ Beech

$\square$ Ash

$\square$ Black Cherry

$\square$ White Oak

$\square$ Red Oaks

$\square$ Other Hardwoods 